\title{
Flow and Fracture of Dental Alloys \\ Determined by a Microbend Tester
}

\author{
KAMAL ASGAR and FLOYD A. PEYTON \\ University of Michigan School of Dentistry, Ann Arbor, Michigan
}

The microstructure of an alloy is the fundamental variable on which the mechanical properties of an alloy depend. For testing the mechanical properties, however, common tests, such as tensile strength or hardness, are generally used. This may be due to the fact that the microstructure study is more complicated and time-consuming. The common method of microstructure study is to perform a series of tensile tests and then obtain the microstructure of the specimens after the tests are completed so as to correlate the structure with the performance data. The actual contribution of each observable microstructure to flow and fracture is rather difficult to detect. When the structure is examined after the fracture has taken place, some of the evidence is lost that would have been available if continuous observation of the structure had been possible.

In 1955 Flinn and Trojan ${ }^{1}$ developed an apparatus by means of which the microstructure of an alloy under stress can be studied. The stress can be increased while the microstructure is under observation. Thus any changes that may take place can be detected in any of the phases. When an alloy with a complicated microstructure is studied, the microbend test shows its main advantage, since it is rather difficult to predict how the different phases of a complicated structure will behave under different stresses. With this test the effect of such stress on various phases may be continuously watched under the microscope. The purpose of this study was to observe the behavior of different phases of cobalt-base and gold alloys used in dentistry for partial denture framework when they were subjected to bending stresses.

\section{EXPERIMENTAL METHODS}

In casting cobalt-base alloys* a phosphate-bonded investment $\dagger$ was used, whereas a calcium sulfate-bonded investment $\ddagger$ was used for casting the gold alloys. By changing the metal casting temperature and varying the mold temperature, it was possible to obtain different types of microstructure. ${ }^{2}$ The test pieces were about 1 inch long, with

Presented before the Dental Materials Group of Chicago, Illinois, March, 1960.

This study was supported by a grant from the Office of Naval Research, contract No. NR-180-360, to the University of Michigan, School of Dentistry.

Submitted by Kamal Asgar to H. H. Rackham Graduate School of the University of Michigan as part of the thesis required for the Ph.D. degree.

Received for publication July $3,1961$.

* Stellite 21.

† Ransom and Randolph No. 711.

$\ddagger$ Ransom and Randolph Gray. 
a square cross-section of $\frac{1}{16}$ inch. Because of the difference in cooling rate, which may alter the microstructure of the periphery, the specimens were not cast to the desired size. The test pieces were cast in a larger size and then machined to the desired dimensions. In machining the pieces, extreme care was exercised so as not to create any excessive heat. By dipping the pieces into water frequently, the specimens were kept cool. When the desired sizes were obtained, they were imbedded in a plastic type of material and polished with successively finer grits of paper and polishing cloths.

The cobalt-base alloys were etched electrolytically with low current produced by a 6-volt battery, using a 2 per cent solution of chromic acid as an electrolyte. ${ }^{3}$ The gold alloys, however, were etched in a mixture of potassium cyanide and ammonium persulfate solution. ${ }^{4}$ The specimens, after being prepared and etched, were placed in the Flinn strain viewer, and the tests proceeded. In Figure 1 is shown the apparatus used for this purpose.

\section{RESULTS}

A total of 20 specimens of cobalt-base and gold alloys was tested by the microbend test. While these specimens exhibited varying microstructure because of the different casting metal and mold temperatures, the results obtained from the microbend test were reproducible. It was believed, therefore, that additional test specimens would not reveal any more information. The microbend apparatus used consisted of two pins to hold the specimen from moving backward and another piece of metal to cover the specimen, in order to prevent it from rotating. As the knob on the screw was turned, a force was applied to the specimen, and, since the specimen would not move backward or turn, it could only bend. This arrangement was very similar to having a beam with both ends freely supported, with a concentrated load applied perpendicular to the axis of the beam. In this way, the microstructure of the alloy was studied under stress caused by bending. In Figure 2 is shown a photograph of one of these specimens under the microbend test.

When a beam is bent, the molecules on the convex side undergo extension, and the molecules on the concave side experience compression. There also exists a surface in which the molecules undergo no strain during bending. This surface is called the "neutral surface," and its intersection with any cross-sectional plane is called the "neutral axis." The magnitude of tension or compression experienced by the molecules depends on the distance of the molecule from the neutral axis. The molecules located on the edge of a specimen are subjected to the highest tension or compression, depending on whether they are on the convex or the concave side.

It had been believed that cobalt-base alloys were brittle. The microstructure observed in this study, however, showed that the matrix material is quite ductile. In Figure 3 the ductility of the matrix material can be observed. The steplike lines shown on the photomicrograph represent the slip planes on the specimen. Slip, by definition, is a process of plastic deformation by the irreversible shear displacement of one part of a metal crystal relative to another. An alloy which can stand such an amount of slip without showing any cracks cannot be considered brittle.

It was believed that it would be an interesting observation to find out which is the most brittle phase of cobalt-base and a gold alloy and where the cracks originate. It was observed that if the specimen contained any type of porosity, regardless of 


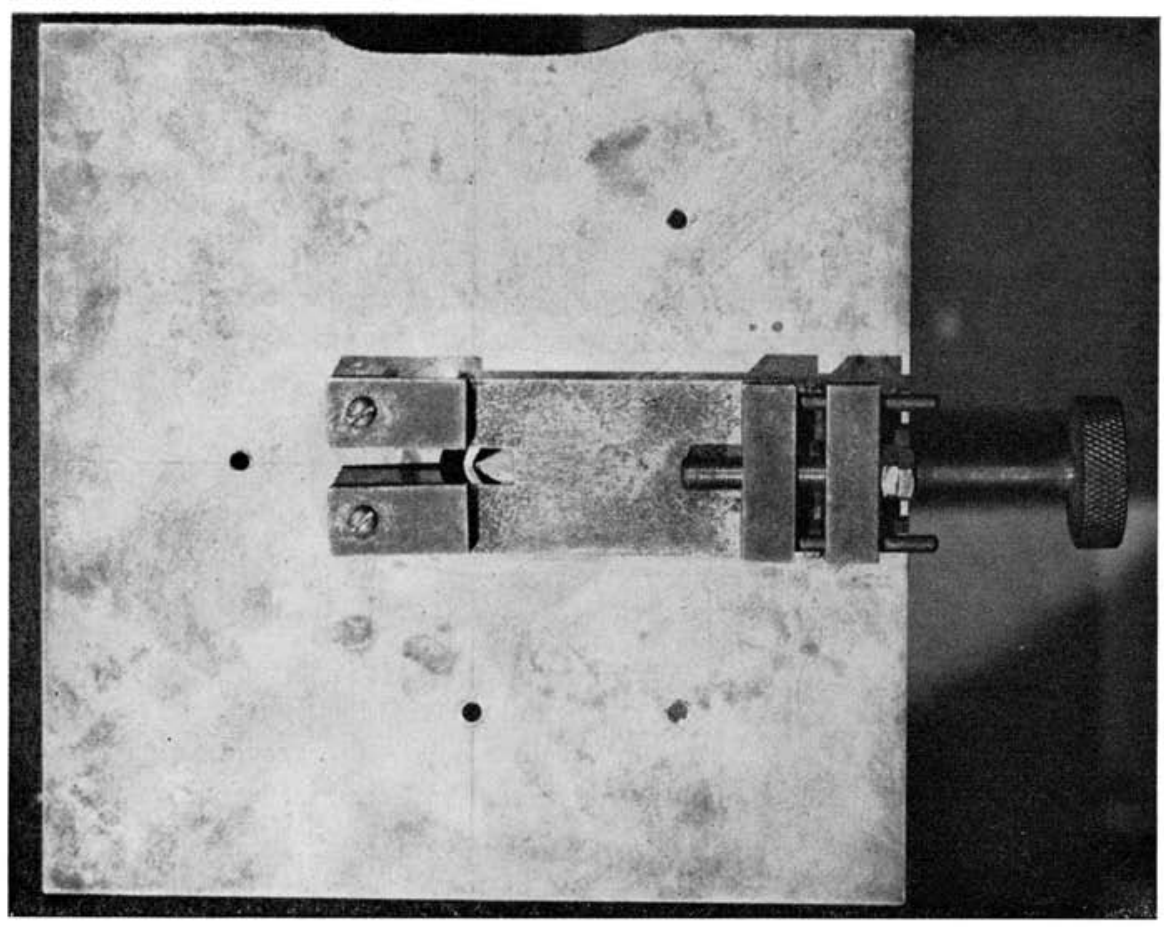

FIG. 1.-Microbend tester

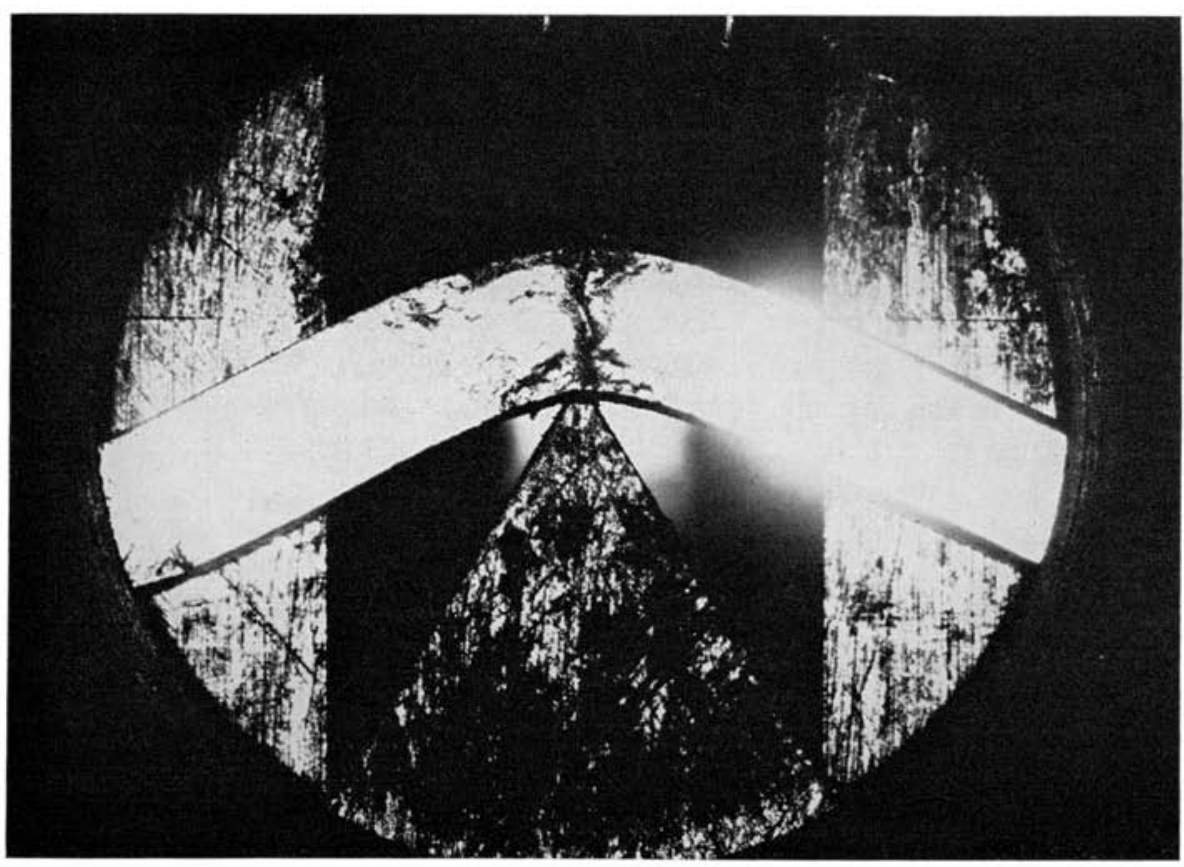

FIG. 2.-Photograph of a specimen under microbend test 
whether cobalt-base or gold, cracks most likely originated around this area, as was expected. The behavior of each phase can be studied only if the specimens are sound and free of porosities. When the specimens were subjected to a load, the slip planes were always first to appear, without any phase exhibiting change in color. These planes always appeared first on the convex side of the specimen and, after the bending of the specimen was increased, also appeared on the concave side. At any given time the extent and the severity of these slip planes were greater on the tension side than on the compression side. The first phase affected by loading the specimen was the dark, black islands which were usually found close to the grain boundary. This phase was identified by Badger and Sweeney as eutectoid. ${ }^{5}$ In Figures 4 and 5 are shown the photo-

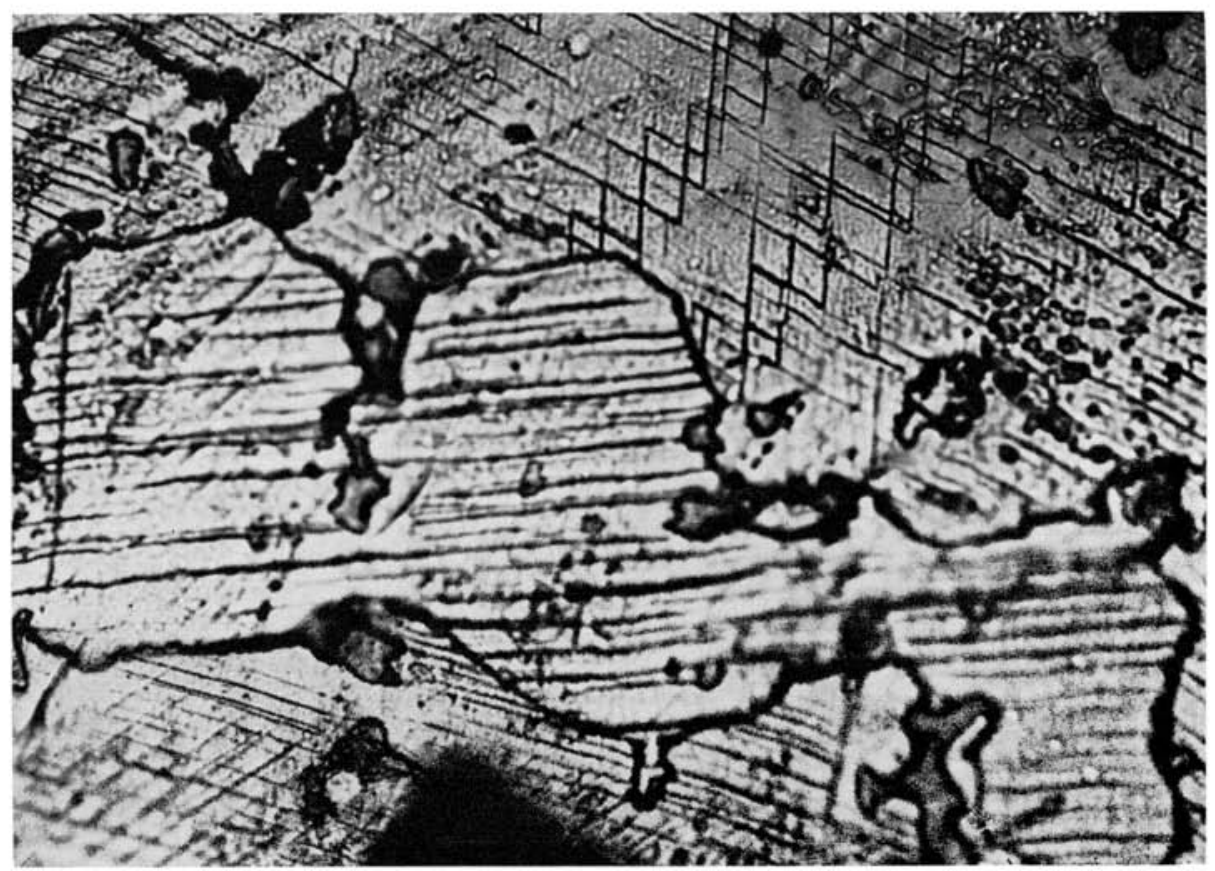

Frc. 3.-Traces of the slip planes on cobalt-base alloy. (Orig. Mag. $\times 500$.)

micrographs of this area at the beginning and at the end of the test. From the presence of slip planes on the photomicrograph in Figure 4, it can be seen that the stress on the specimen was comparatively low. As the stress increased, the darkness of the islands also increased, and the matrix around them blurred until all the black islands were connected to one another and the cracks were initiated. This can be seen in Figure 5 . From the same figure it is also clear that the crack did not follow the grain boundary, but, rather, it followed along the islands. This indicates that the most brittle phase in the material is the black islands, the eutecoid structure.

In a different specimen, an area on the convex side of the specimen was considered the area in which a crack was most likely to develop. As the load was increased, a series aof photomicrographs was taken, which are shown in Figures 6 through 9. These photomicrographs show changes in the microstructure of the alloy which occurred until the specimen cracked. The change in the extent of the crack from one photo- 


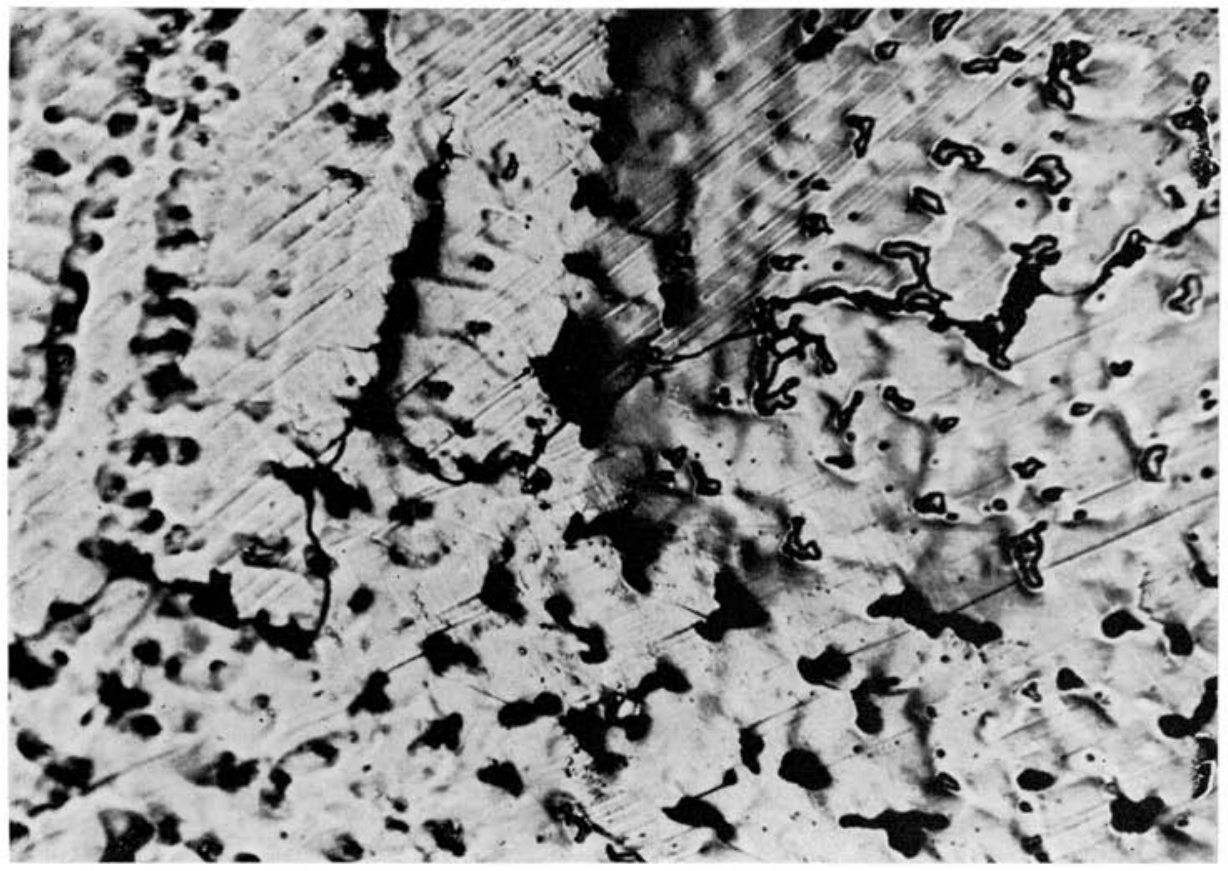

Fig. 4.-Microstructure of eutectoid areas and slip planes. Comparatively low stress. (Orig. Mag. $\times 500$.

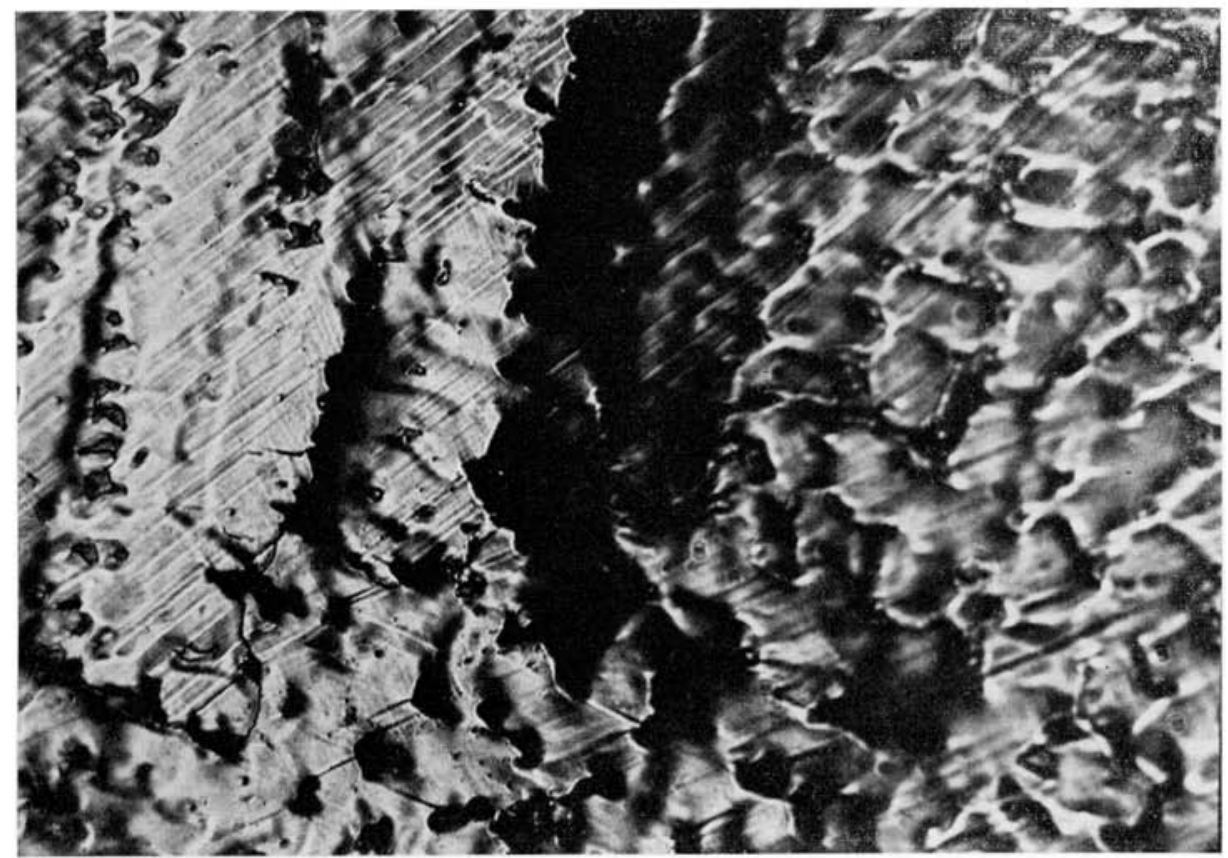

Fig. 5.-Same area as shown in Fig. 4. Comparatively high stress. Eutectoid areas are connected. The crack initiated along the dark areas, which have eutectoid composition. (Orig. Mag. $\times 500$.) 


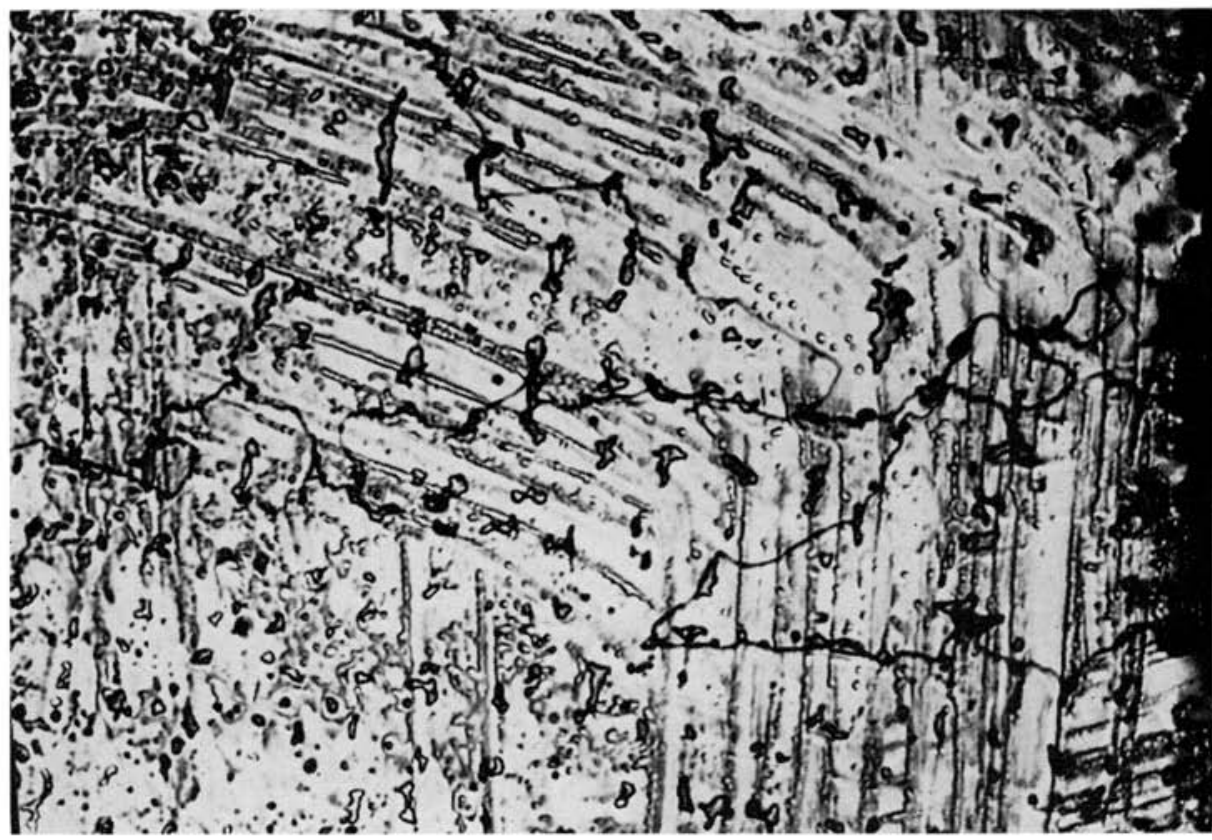

FIG. 6.-Microstructure of an area where a crack is most likely to develop. (Orig. Mag. $\times 500$.)

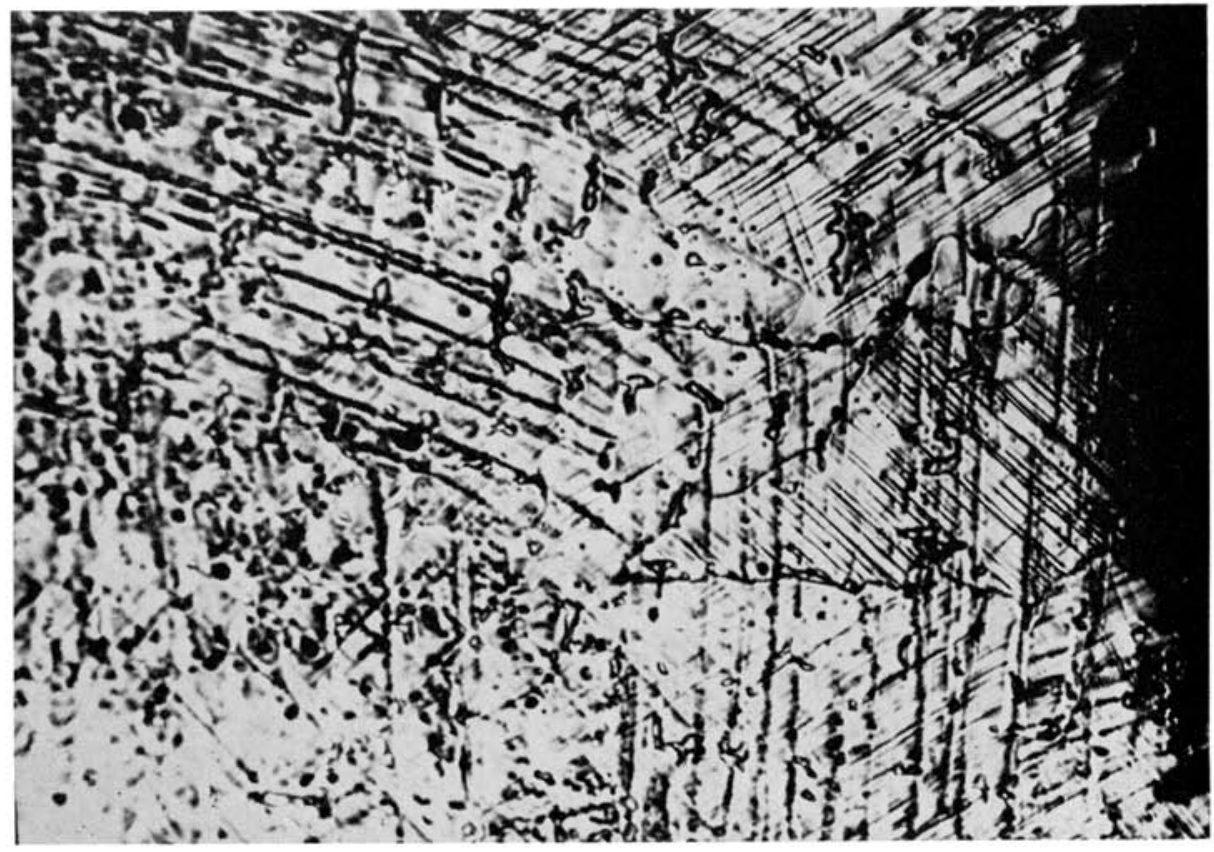

Fig. 7.-Microstructure of the same area as shown in Fig. 6. Stress is increased. (Orig. Mag. $\times 500$.) 


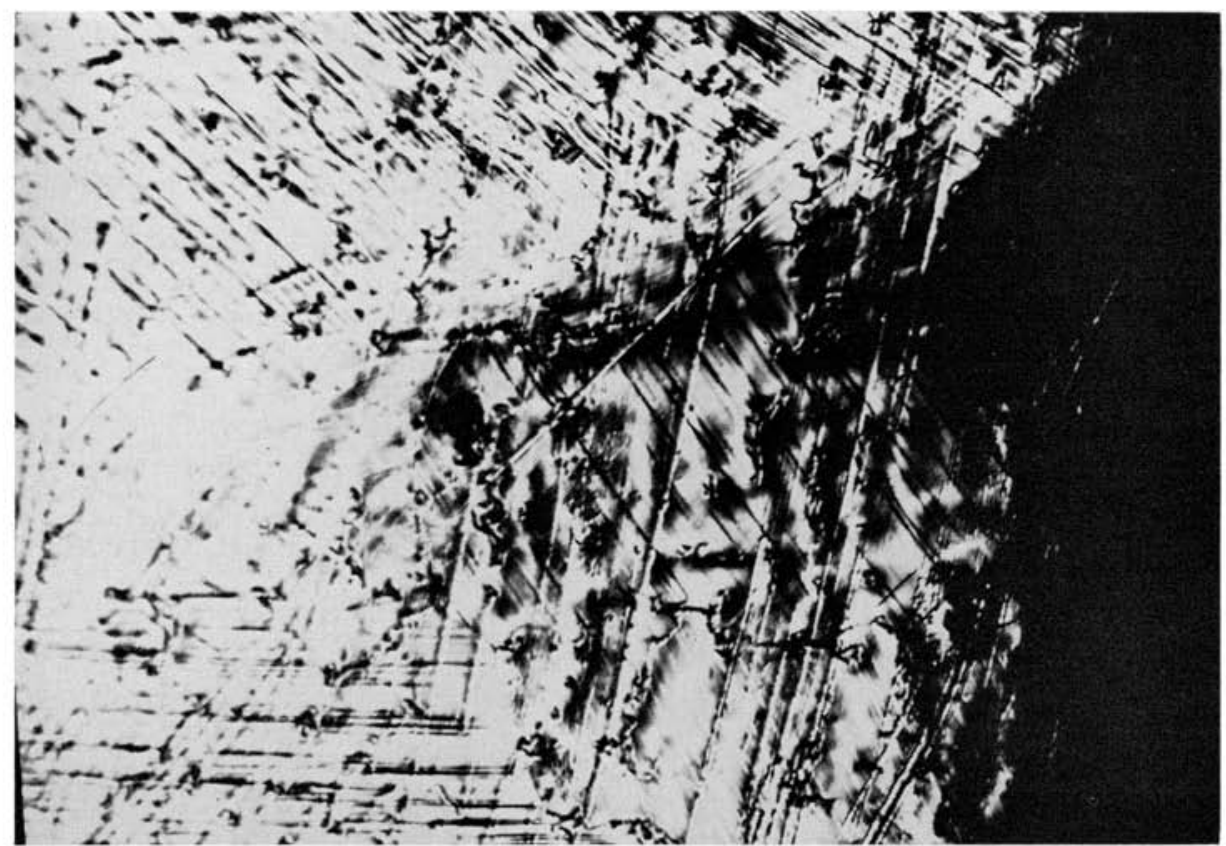

FIG. 8.-Microstructure of the same area as shown in Fig. 6. Increase in the amount of stress is noticeable by severity of slip planes. (Orig. Mag. $\times 500$.

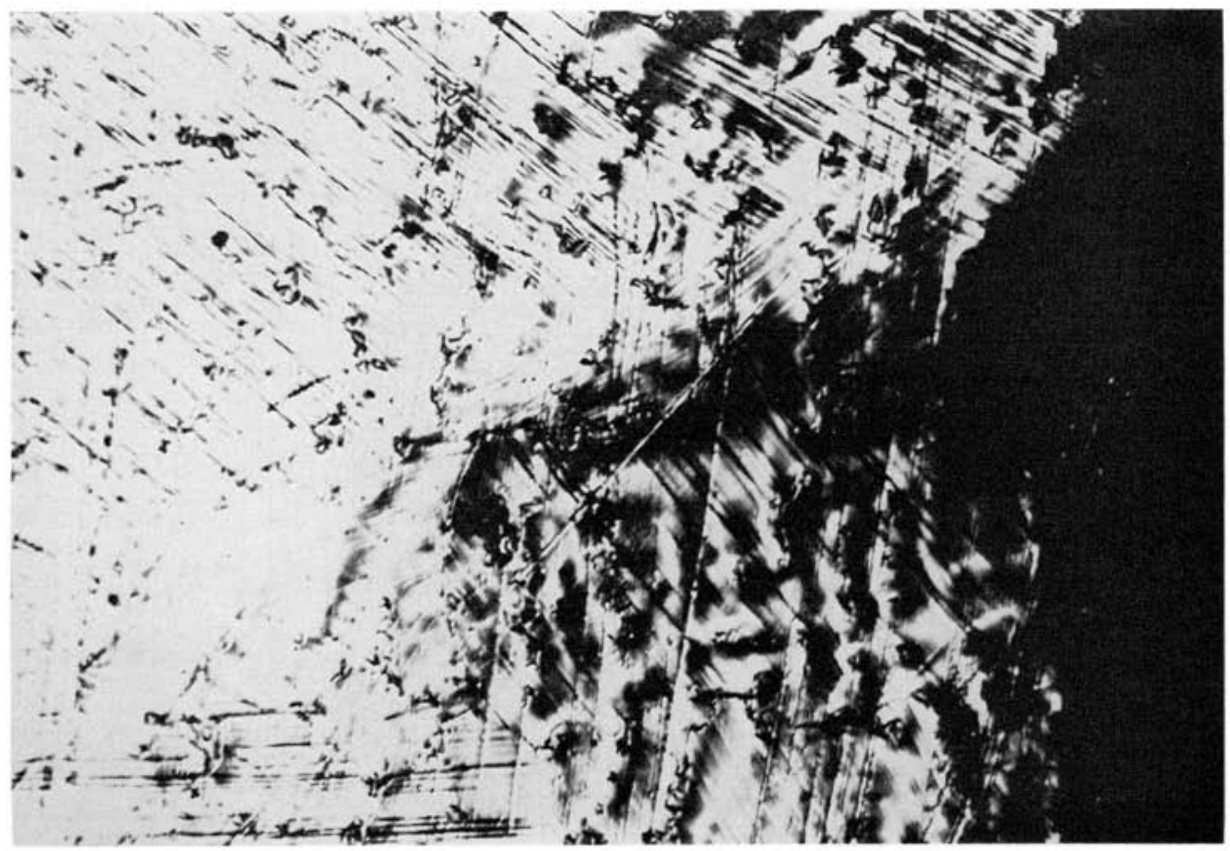

Fig. 9.-Microstructure of the same area as shown in Fig. 6. Crack has developed. (Orig. Mag. $\times 500$. 
micrograph to another may be seen from the direction of the slip planes. Similar results may occur on the concave side of the specimen. It was observed in cobalt-base specimens that whenever the area under high stress was free from porosity and dark, black islands, the crack originated at the grain boundary. In Figure 10 is shown a photomicrograph at 800 magnification of a crack initiated at the grain boundary.

Gold specimens, however, behaved differently. It was observed that gold specimens under the same test did not initiate a crack, but rather crumbled. In Figures 11 through 14, the behavior of gold alloys can be observed.

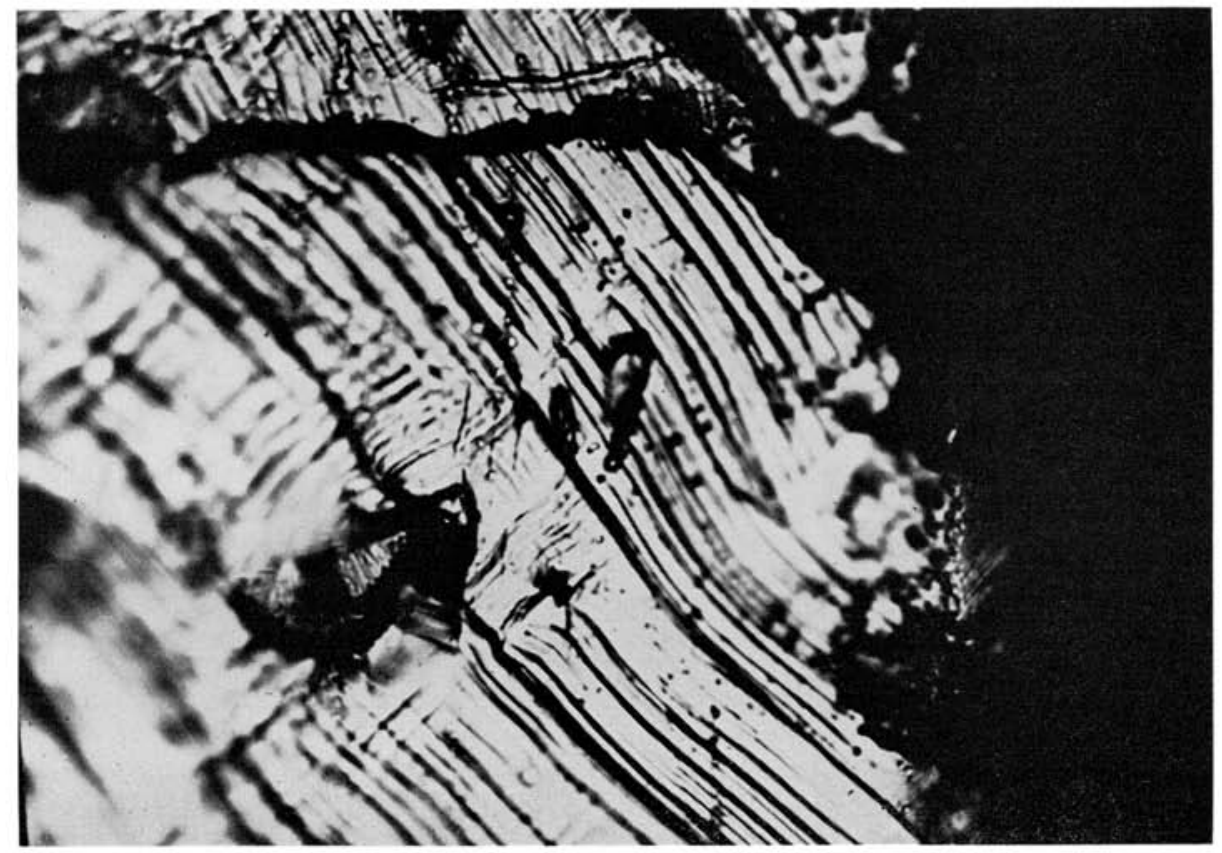

FIG. 10.-Microstructure of a grain boundary where crack is initiated. (Orig. Mag. $\times 800$.)

\section{DISCUSSION}

Tests have been established for determining specific properties of a material. Most of these tests reveal the value of a specific property; however, they are tests that may not necessarily fully define the property. For example, a common way of measuring ductility is to measure the per cent of elongation of the material. From the per cent of elongation values the degree of ductility of an alloy and the ductility of one alloy compared with that of another may be judged. It should be recalled, however, that the elongation of the specimen is obtained under tensile force, and the per cent of elongation is a means of measuring ductility of an alloy when it is stretched. This type of measurement provides the information desired in the case of dental inlay golds which may have to be burnished. Alloys with higher elongation values are burnished more easily. In cast partial denture framework however, the ductility of an alloy is used to serve a different purpose. In this case, the ductility of the alloy enables bending and adjusting of the clasps. The clasps should not, of course, fracture during their 


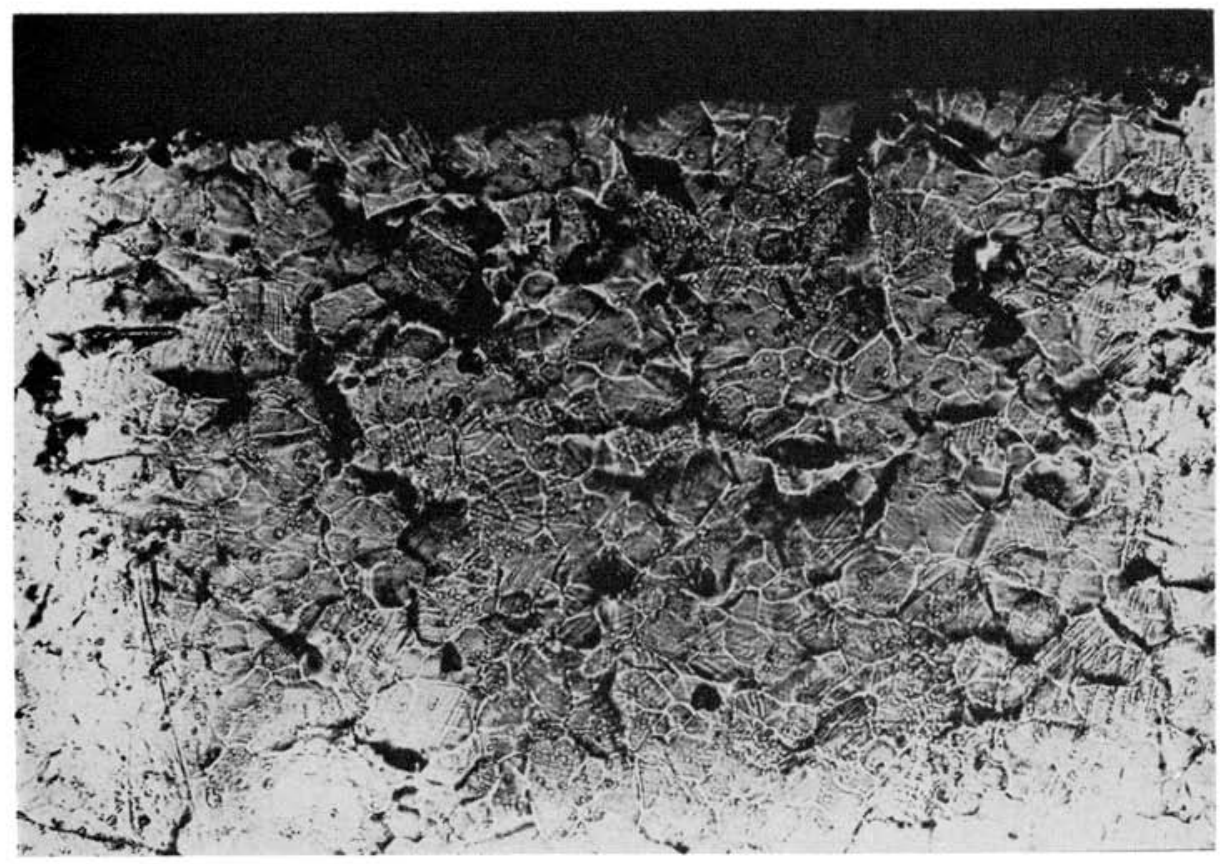

Fig. 11. - Microstructure of gold alloy under stress. (Orig. Mag. $\times 100$.)

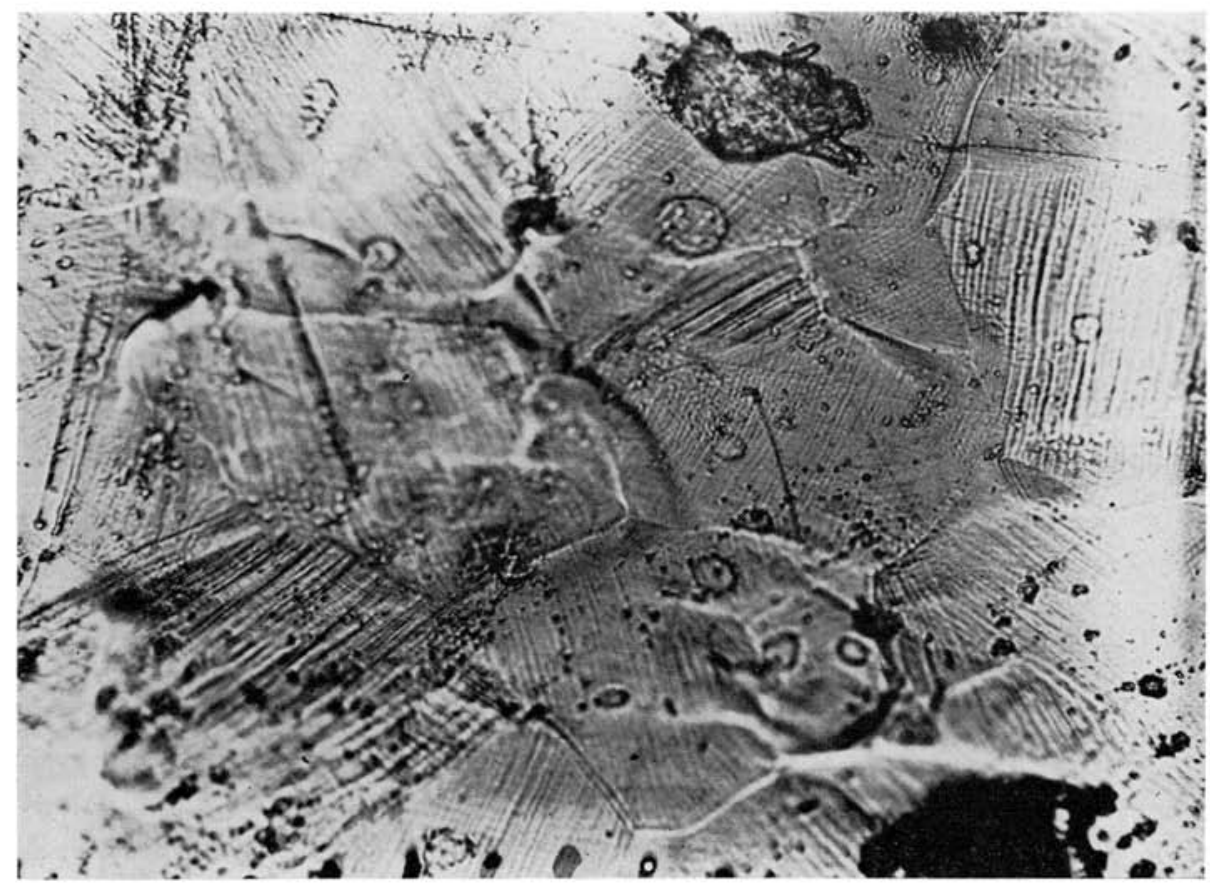

Fig. 12.-Microstructure of the same area as shown in Fig. 11. Traces of slip planes are evidence of the specimen being stressed. (Orig. Mag. $\times 500$.) 


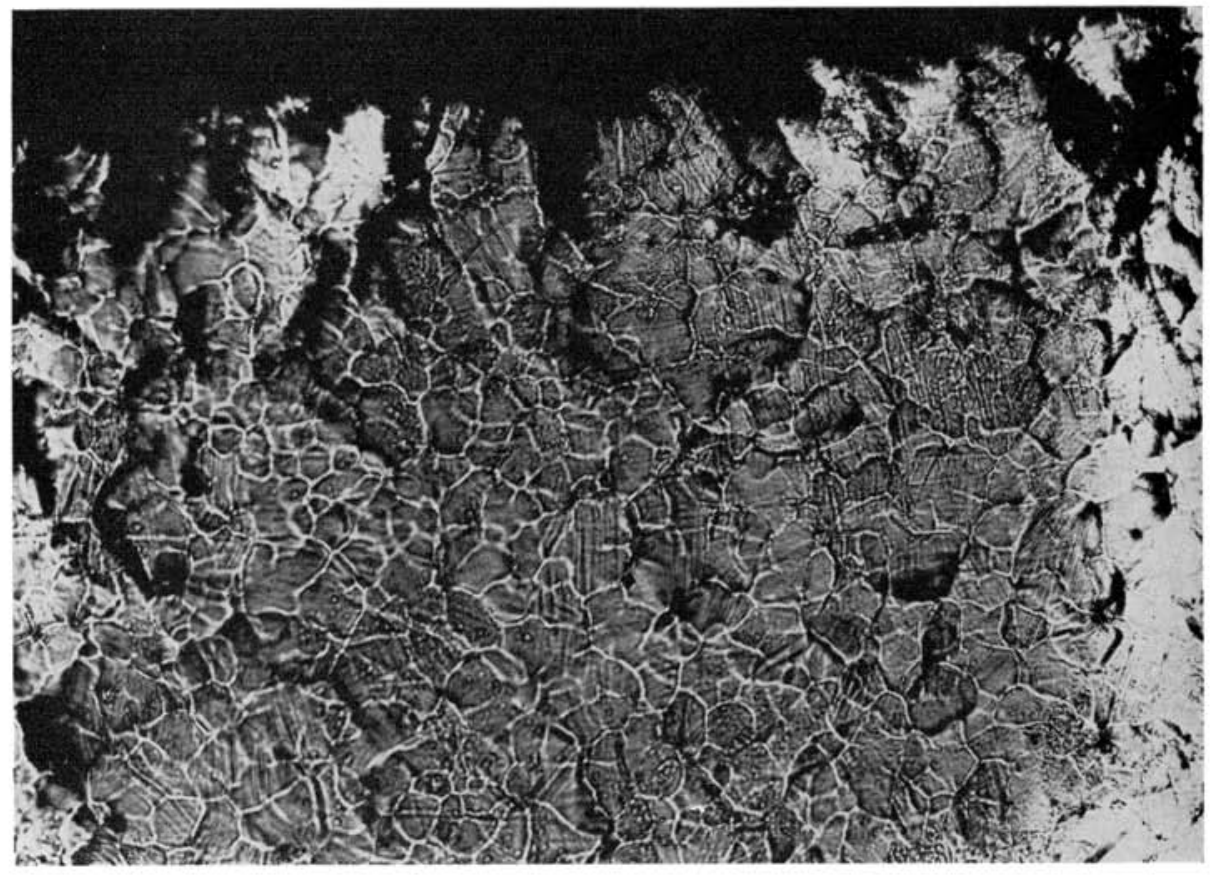

FIG. 13.-Microstructure of the same area as shown in Fig. 11. Stress is increased. (Orig. Mag. $\times 100$.

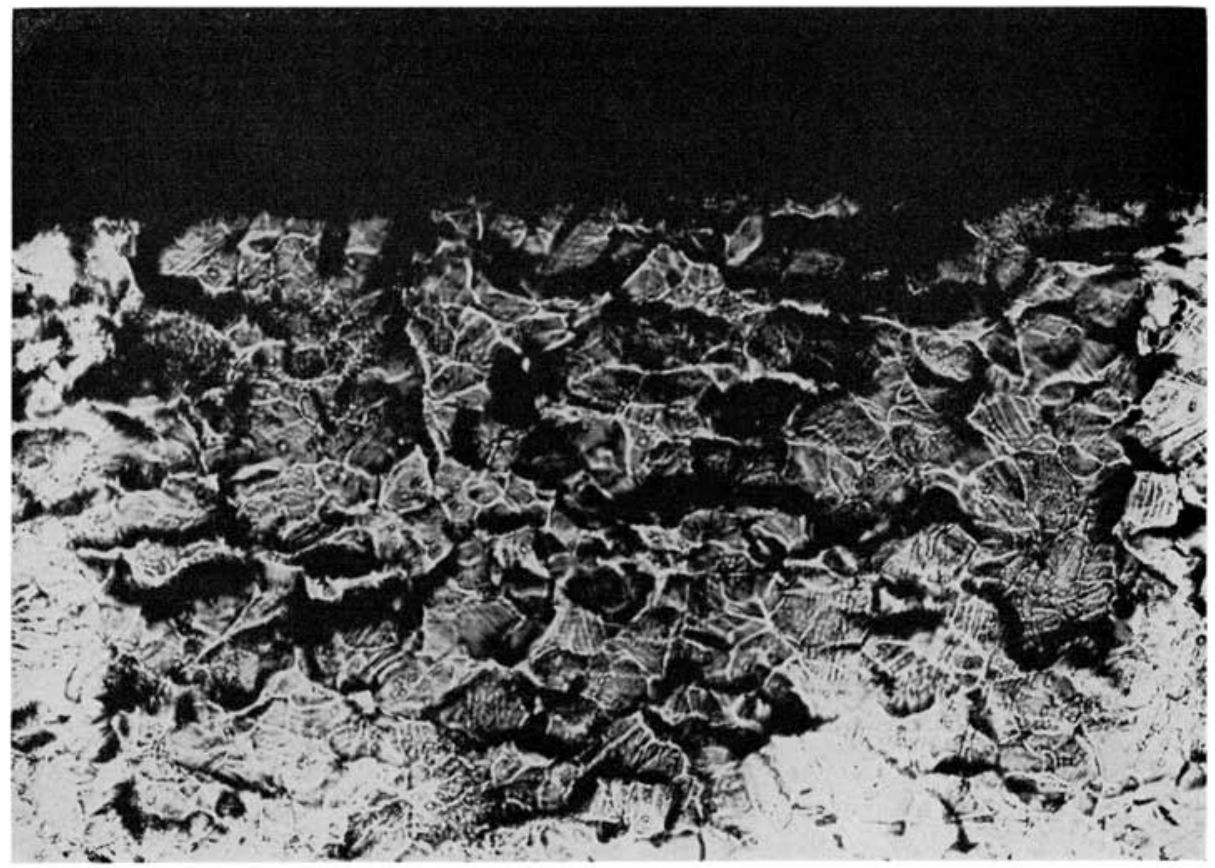

FIG. 14.- Microstructure of the same area as shown in Fig. 11. Stress is still more increased. (Orig. Mag. $\times 100$.) 
adjustment or during the time they are in service. It is possible that the per cent of elongation does not provide all the information desired, and another type of test, based on bending and fatigue, might be designed for partial denture alloys. The microbend test, used in this study, is not necessarily the answer to the above-mentioned problem, but it shows what may take place when these alloys are being bent.

From this study it can be deduced that, if the formation of the dark islandseutectoid structures-in cobalt-base alloys are prevented by the addition of another alloying element or by some other means, then the alloy may become more suitable for use in partial denture applications. For example, in a series of castings in which the molten metal was heated to $2800^{\circ} \mathrm{F}$. and cast into a mold of $1600^{\circ} \mathrm{F}$., the cast pieces were quite ductile. Such cast specimens may not possess an acceptable surface for practical usage, but, they are more ductile, and their microstructure is somewhat different. A typical microstructure of this series under Flinn microbend tester is shown in Figure 3.

The low amount of permanent deformation observed in these alloys as used in dentistry may be due to the existence of microporosity, in which case the cast pieces fracture before showing any considerable amount of permanent deformation. In some other samples tested in bending, the specimen broke easily without developing an extensive amount of slip planes, where the microstructure showed some porosity. It may be hypothesized that, because of the shape of dental castings, which are castings of very thin pieces with comparatively large areas, it is difficult to obtain completely sound castings, and the probability of having a certain amount of microporosity in some part of the casting is great. This type of porosity has a comparatively small effect on the ultimate tensile strength of the alloy, which allows the cast pieces to be serviceable; however, it does lower its elongation or permanent deformation values considerably. ${ }^{6}$ Possibly this is the reason that these alloys are known in dentistry as brittle and materials with low elongation values. No doubt exists that the elongation of cobalt-base alloys is lower than that of gold alloys in the softened condition. The cobalt-base alloys may be capable of higher elongation, however, than that usually obtained in dental castings by improved control of casting conditions and choice of alloy.

\section{SUMMARY}

The black areas of the sound castings, which were identified by Badger and Sweeney as eutectoid areas, comprised the most brittle phase in cobalt-base alloys.

The matrix of cobalt-base alloys was found to be quite ductile and to withstand a considerable amount of bending. The presence of microporosities in the cast pieces was the first cause of fractures when the specimens were bent. When the sound cobalt-base castings did not possess dark eutectoid areas, the fracture initiated at the grain boundary.

Gold alloys tested did not fracture in the same manner as cobalt-base specimens. They crushed and deformed until they broke.

Further investigation in microbend tests may yield some useful results for dentistry. 


\section{REFERENCES}

1. Flins, R. A., and Trojan, P. K. Examination of Microstructures under Varying Stress, Metal Progr. 68:88, 1955.

2. Asgar, K., and Peyton, F. A. Effect of Microstructure on the Physical Properties of Cobalt-Base Alloys, J. D. Res., $40: 63,1961$.

3. Faulkner, W. H. Haynes Stellite Company, Kokomo, Indiana. Personal communication, 1958.

4. Wise, E. M. The Metallography of Precious Metals. In Lyman (ed.), Metal Handbook, p. 1109. Cleveland: American Society Met., 1948.

5. BADGER, F. S., and SWEENEY, W. O. Metallurgy of High Temperature Alloys Used on Current Gas Turbine Designs: Symposium on Material for Gas Turbines, p. 99. Philadelphia: American Society for Testing Materials, 1946.

6. Asgar, K., and Peyton, F. A. Effect of Casting Conditions on Some Mechanical Properties of Cobalt-Base Alloys, J. D. Res., $40: 73,1961$. 